\title{
Flow Rate Unit
}

National Cancer Institute

\section{Source}

National Cancer Institute. Flow Rate Unit. NCI Thesaurus. Code C82579.

The unit of measure for the rate of infusion. 